\title{
EVALUASI PERESEPAN PADA PASIEN GERIATRI DI KLINIK PENYAKIT DALAM INSTALASI RAWAT JALAN RSUD K.R.M.T WONGSONEGORO SEMARANG
}

\author{
Tri Mulyani ${ }^{1}$, Fef Rukminingsih ${ }^{2}$ \\ ${ }^{1,2}$ Politeknik Katolik Mangunwijaya Semarang \\ Email korespondensi : fefrukminingsih@gmail.com
}

\begin{abstract}
ABSTRAK
Masalah medis yang kompleks pada pasien lansia menyebabkan lansia mendapatkan peresepan polifarmasi. Polifarmasi merupakan salah satu faktor predisposisi terjadinya Drug Related Problems (DRPs). Beers Criteria merupakan salah satu metode untuk menghindari terjadinya DRPs. Penelitian ini bertujuan untuk mengevaluasi peresepan pada pasien geriatri berdasarkan Beers Criteria tahun 2015 di klinik penyakit dalam instalasi rawat jalan RSUD K.R.M.T Wongsonegoro Semarang. Penelitian ini merupakan penelitian deskriptif observasional dengan menggunakan data retrospektif dari rekam medis pasien geriatri di klinik penyakit dalam instalasi rawat jalan RSUD K.R.M.T Wongsonegoro Semarang periode Oktober-Desember 2017. Sebanyak 300 data rekam medik diambil secara acak sederhana sebagai sampel. Data setiap pasien hanya diambil sekali selama periode penelitian. Pasien adalah peserta JKN dan berusia $\geq 60$ tahun. Data yang diperoleh kemudian diidentifikasi menggunakan Beers Criteria tahun 2015. Berdasarkan peresepan dari 300 pasien geriatri di klinik penyakit dalam RSUD K.R.M.T Wongsonegoro Semarang diketahui sebanyak 88,33\% pasien mendapatkan peresepan obat-obat yang termasuk dalam Beers Criteria tahun 2015. Lima jenis obat yang paling banyak diresepkan adalah $\mathrm{Na}$ diklofenak, omeprazole, digoxin, ranitidin, dan diazepam. Obat-obat yang termasuk dalam Beers Criteria adalah obat-obat yang sebaiknya tidak diberikan pada pasien geriatri sehingga perlu kewaspadaan dalam penggunaan obat-obat tersebut.
\end{abstract}

Kata kunci : Geriatri, Polifarmasi, Beers Criteria, RSUD K.R.M.T Wongsonegoro 


\title{
EVALUATION OF PRESCRIPTION AT GERIATRIC PATIENTS BASED ON THE BEERS CRITERIA 2015 AT THE INTERNAL MEDICINE CLINIC IN THE OUTPATIENT INSTALLATION OF K.R.M.T WONGSONEGORO HOSPITAL SEMARANG
}

\begin{abstract}
The medical problems encountered in geriatric patients cause the prescribing to be susceptible to polypharmacy so that the possibility of creating Drug Related Problems (DRPs) is likely. Beers Criteria is one method to avoid the occurrence of DRPs. This study aims to evaluate prescribing of geriatric patients based on the Beers Criteria 2015 at the internal medicine clinic in the outpatient installation of K.R.M.T Wongsonegoro Hospital Semarang. This research was an descriptive observational study using retrospective data from geriatric patients' medical records at the internal medicine clinic in the outpatient installation of K.R.M.T Wongsonegoro Hospital Semarang in the period October-December 2017. A total of 300 medical records were taken at simple random as samples. Data for each patient were only taken once during the study period. The patient is a national health insurance participant and is $\geq 60$ years old. The data obtained was then identified using Beers Criteria 2015. Based on the prescription of 300 geriatric patients in the internal medicine clinic in Wongsonegoro Hospital Semarang, it is known that $88,33 \%$ patients received prescription included in Beers Criteria 2015. The five medicine most prescribed are Na diclofenac, omeprazole, digoxin, ranitidine, and diazepam. Medications included in Beers Criteria are medicine that should not be given to geriatric patients so that caution is needed in the use of these medicine.
\end{abstract}

Keywords : Geriatric, Polypharmacy, Beers Criteria, K.R.M.T Wongsonegoro Hospital

\section{PENDAHULUAN}

Geriatri merupakan cabang
disiplin ilmu kedokteran yang
mempelajari aspek kesehatan dan
kedokteran pada warga lanjut usia
(lansia) yang berupa promosi,
pencegahan, diagnosis, pengobatan, dan rehabilitasi. Pasien geriatri adalah pasien lansia dengan multi penyakit dan atau gangguan akibat penurunan fungsi organ, psikologi, sosial, ekonomi dan lingkungan yang membutuhkan

pelayanan kesehatan secara terpadu dengan pendekatan multidisiplin yang bekerja secara interdisiplin. Lansia adalah penduduk yang berusia 60 tahun atau lebih (Kemenkes RI, 2014).

Berdasarkan data World Population Prospects, pada tahun 2015 diketahui jumlah lansia berkisar 901 juta orang dan diprediksi mengalami kenaikan sampai 1,4 milyar pada tahun 
2030 dan menjadi 2,1 milyar pada tahun 2050. Indonesia diprediksi masuk dalam 10 besar populasi lansia terbesar di dunia pada tahun 2050 (United Nations, 2015).

Lansia pada umumnya memiliki lebih dari satu penyakit (multidiagnosa), bersifat kronis yang dapat menimbulkan kecacatan bahkan kematian, dan rentan terhadap berbagai penyakit akut yang diperberat dengan adanya penurunan daya tahan tubuh (Dasopang dkk, 2015). Masalah medis yang kompleks pada pasien lansia menyebabkan lansia mendapatkan peresepan polifarmasi (Anggriani dkk, 2016). Polifarmasi merupakan penggunaan obat sebanyak lima macam atau lebih untuk satu pasien dalam satu resep. Polifarmasi secara signifikan dapat meningkatkan risiko interaksi obat dengan obat. Polifarmasi merupakan salah satu faktor predisposisi terjadinya Drug Related Problems (DRPs) (Tobat dkk, 2015).

DRPs terkait pemberian obat pada pasien geriatri meliputi terapi obat yang tidak sesuai, potensi interaksi obat, dosis yang tidak tepat, pemakaian obat yang tidak perlu, pemilihan jenis obat yang tidak tepat, dan efek samping obat (Rahmawati dan Sunarti, 2014). Pemberian obat yang tidak tepat pada pasien geriatri dapat dihindari dengan menggunakan metode Beers Criteria (Syuaib dkk, 2015). Beers Criteria dapat mengidentifikasi potensi ketidaktepatan penggunaan obat pada pasien geriatri meliputi obat-obat yang sebaiknya dihindari atau dapat digunakan pada pasien geriatri tetapi dengan perhatian khusus (Syuaib dkk,
2015). Beers Criteria memiliki kelebihan, yaitu penerapannya yang sederhana, mudah diikuti, data yang diperoleh memberikan hasil yang sama pada setiap pengukuran, dan biayanya lebih murah (Negara dkk, 2016).

RSUD K.R.M.T Wongsonegoro

Semarang merupakan rumah sakit milik Pemerintah Daerah Kota Semarang yang memiliki fasilitas dan kemampuan pelayanan medis spesialistik salah satunya adalah klinik penyakit dalam. Berdasarkan data dari Sistem Informasi Managemen Rumah Sakit (SIM-RS) tahun 2017 diketahui sebanyak 37,5\% dari pasien klinik penyakit dalam adalah pasien geriatri dengan usia berkisar 60 tahun ke atas. Penelitian ini bertujuan untuk mengevaluasi peresepan obat pada pasien geriatri di klinik penyakit dalam RSUD K.R.M.T Wongsonegoro Semarang. berdasarkan Beers Criteria.

\section{METODE PENELITIAN}

Penelitian ini merupakan penelitian deskriptif observasional dengan menggunakan data retrospektif yang diperoleh dari rekam medis pasien geriatri yang menjalani pengobatan di klinik penyakit dalam RSUD K.R.M.T Wongsonegoro. Kriteria inklusi dalam penelitian ini adalah pasien geriatri di klinik penyakit dalam instalasi rawat jalan RSUD K.R.M.T Wongsonegoro Semarang periode Oktober - Desember 2017, peserta JKN dan berusia $\geq 60$ tahun. Sampel diperoleh dengan cara simple random sampling, yang dihitung berdasarkan rumus Slovin. Rata-rata kunjungan pasien JKN di klinik penyakit dalam adalah 1.382 pasien per 
bulan. Taraf signifikansi yang digunakan adalah 0,1 maka banyaknya sampel yang diambil setiap bulan adalah 100 pasien. Setiap pasien hanya mendapat kesempatan satu kali diambil datanya selama periode penelitian. Data rekam medis yang diambil meliputi nomor rekam medis, umur, jenis kelamin, diagnosa dan peresepan. Data yang diperoleh kemudian di analisis secara kualitatif dan kuantitatif.

Analisis kualitatif dilakukan dengan cara mengelompokkan data pasien berdasarkan umur, jenis kelamin, diagnose dan peresepan. Analisa kuantitatif dilakukan dengan menghitung persentase peresepan berdasarkan diagnosa dan jenis obat yang termasuk dalam Beers Criteria tahun 2015 (American Geriatrics Society, 2015).

\section{HASIL DAN PEMBAHASAN}

Berdasarkan hasil sampling dan penelusuran data rekam medik diketahui sebanyak 300 pasien yang memenuhi kriteria inklusi. Karakteristik pasien geriatri di poliklinik penyakit dalam RSUD K.R.M.T Wongsonegoro Semarang periode Oktober-Desember 2017 dapat dilihat pada tabel I.

Tabel I. Karakteristik pasien geriatri di poli penyakit dalam RSUD K.R.M.T Wongsonegoro Semarang periode Oktober-Desember 2017.

\begin{tabular}{lcc}
\hline \multicolumn{1}{c}{ Karakteristik } & Jumlah (orang) & Persentase (\%) \\
\hline Usia (tahun) & 201 & 67,00 \\
$60-69$ & 70 & 23,33 \\
$70-79$ & 29 & 9,67 \\
$\geq 80$ & 300 & 100 \\
Jumlah & & \\
Jenis Kelamin & 142 & 47,33 \\
Laki-laki & 158 & 52,67 \\
Perempuan & 300 & 100 \\
Jumlah & & \\
Diagnosa utama & 81 & 27,00 \\
Hipertensi & 70 & 23,33 \\
Diabetes Mellitus(DM) tipe 2 & 53 & 17,67 \\
Gagal jantung kongestif (CHF) & 49 & 16,33 \\
Ischemic heart disease (IHD) & 16 & 5,33 \\
Penyakit paru obstruksi kronis & 9 & 3,00 \\
Acute myocard infark (AMI) & 22 & 7,34 \\
Lain-lain & 300 & 100 \\
Jumlah & & \\
Jumlah Penyakit Penyerta & 47 & 15,67 \\
Tidak ada & 149 & 49,67 \\
1 & 104 & 34,66 \\
$\geq 2$ & 300 & 100 \\
Jumlah & &
\end{tabular}


Berdasarkan Tabel I diketahui bahwa pasien geriatri paling banyak berusia 60-69 tahun yaitu sebanyak 201 pasien $(67 \%)$ karena angka harapan hidup penduduk Indonesia adalah 70,1 tahun. Jumlah pasien perempuan lebih banyak $(52,67 \%)$ karena angka harapan hidup penduduk perempuan lebih tinggi daripada angka harapan hidup penduduk laki-laki (BPS, 2017). Sebanyak $84,33 \%$ pasien geriatri menderita hipertensi, DM tipe 2, CHF, dan IHD. Berdasarkan hasil Riset Kesehatan Dasar (2013) diketahui bahwa hipertensi, DM tipe 2, CHF dan IHD termasuk dalam 10 besar penyakit degeneratif yang diderita oleh pasien geriatri di Indonesia. Sebanyak 84,33\% pasien geriatri mempunyai penyakit penyerta. Pasien geriatri umumnya menderita lebih dari satu penyakit atau multipatologis dan bersifat kronis, hal ini dikarenakan adanya penurunan fungsi organ tubuh, penurunan status fungsional, perubahan farmakokinetik dan farmakodinamik (Dasopang dkk, 2015).

Distribusi pasien geriatri berdasarkan jumlah item obat dalam resep pasien geriatric di klinik penyakit dalam instalasi rawat jalan RSUD K.R.M.T Wongsonegoro Semarang Periode Oktober - Desember 2017 dapat dilihat pada Tabel II.

Tabel II. Distribusi pasien geriatri berdasarkan jumlah item obat dalam resep pasien geriatri di klinik penyakit dalam instalasi rawat jalan RSUD K.R.M.T

Wongsonegoro Semarang Periode Oktober - Desember 2017

\begin{tabular}{ccc}
\hline $\begin{array}{c}\text { Jumlah item obat } \\
\text { dalam resep }\end{array}$ & Jumlah Pasien & $\begin{array}{c}\text { Persentase } \\
(\%)\end{array}$ \\
\hline$<5$ & 24 & 8,00 \\
5 & 55 & 18,33 \\
6 & 60 & 20,00 \\
7 & 57 & 19,00 \\
8 & 62 & 20,67 \\
9 & 24 & 8,00 \\
10 & 10 & 3,33 \\
$>10$ & 8 & 2,67 \\
\hline Jumlah & 300 & 100 \\
\hline
\end{tabular}

Berdasarkan Tabel II diketahui bahwa sebanyak $92 \%$ pasien geriatri mendapat peresepan polifarmasi. Hal ini disebabkan kondisi pasien geriatri yang multipatologis. Polifarmasi didefinisikan sebagai penggunaan obat dalam jumlah lima atau lebih item obat dalam satu resep (Rambadhe dkk, 2012). Polifarmasi meningkatkan peluang atau kemungkinan adanya obat-obat yang termasuk dalam Beers Criteria semakin besar. 
Beers Criteria bertujuan untuk mengidentifikasi potensi ketidaktepatan penggunaan obat pada pasien geriatri (Syuaib dkk, 2015). Distribusi pasien geriatri berdasarkan diagnosa dan jenis obat di klinik penyakit dalam instalasi rawat jalan RSUD K.R.M.T Wongsonegoro Semarang periode Oktober - Desember 2017 dapat dilihat pada Tabel III.

Tabel III. Distribusi pasien geriatri berdasarkan diagnosa dan jenis obat di klinik penyakit dalam instalasi rawat jalan RSUD K.R.M.T Wongsonegoro Semarang periode Oktober - Desember 2017

\begin{tabular}{cccccccc}
\hline \multirow{2}{*}{ No } & \multirow{3}{*}{ Peresepan } & \multicolumn{4}{c}{ Beers Criteria } & \multicolumn{2}{c}{ Total } \\
\cline { 3 - 7 } & & \multicolumn{2}{c}{ Ada } & \multicolumn{2}{c}{ Tidak } \\
\cline { 3 - 7 } & Dumlah & $(\%)$ & Jumlah & $(\%)$ & Jumlah & $(\%)$ \\
\hline 1 & Diagnosa & 265 & 88,33 & 35 & 11,67 & 300 & 100 \\
2 & Jenis Obat & 487 & 23,98 & 1.544 & 76,02 & 2.031 & 100 \\
\hline
\end{tabular}

Berdasarkan Tabel III diketahui bahwa berdasarkan diagnosa, sebanyak 265 pasien $(88,33 \%)$ di dalam peresepannya terdapat 487 item obat yang termasuk dalam Beers Criteria.

Jenis obat yang termasuk dalam

Beers Criteria harus dihindari penggunaannya, karena memiliki risiko tinggi, efek yang merugikan dan kurang efektif apabila digunakan pada pasien geriatri. Apabila obat-obat tersebut tetap diberikan maka diperlukan kewaspadaan dalam penggunaannya (Hanlon dkk, 2011; American Geriatrics Society, 2015).

Tabel IV. Jenis obat dalam Beers Criteria yang diresepkan di klinik penyakit dalam instalasi rawat jalan RSUD K.R.M.T Wongsonegoro Semarang periode Oktober Desember 2017

\begin{tabular}{|c|c|c|c|}
\hline \multirow{2}{*}{ No } & \multirow{2}{*}{ Nama Obat } & \multicolumn{2}{|c|}{ Beers Criteria } \\
\hline & & Jumlah & Persentase \\
\hline 1 & Na diklofenak & 122 & 25,05 \\
\hline 2 & Omeprazol & 118 & 24,23 \\
\hline 3 & Digoxin & 49 & 10,06 \\
\hline 4 & Ranitidin & 47 & 9,65 \\
\hline 5 & Diazepam & 45 & 9,24 \\
\hline 6 & Metilprednisolon & 17 & 3,49 \\
\hline 7 & Ibuprofen & 12 & 2,46 \\
\hline 8 & Klorfeniramin maleat & 9 & 1,85 \\
\hline 9 & Amitriptilin & 9 & 1,85 \\
\hline 10 & Triheksifenidil & 8 & 1,64 \\
\hline 11 & Codein & 8 & 1,64 \\
\hline
\end{tabular}




\begin{tabular}{clcc}
12 & Cilostazol & 7 & 1,44 \\
13 & Asam mefenamat & 7 & 1,44 \\
14 & Lain-lainnya & 29 & 5,95 \\
\hline \multicolumn{2}{c}{ Total } & 487 & 100 \\
\hline
\end{tabular}

Berdasarkan Tabel IV diketahui bahwa Na diklofenak, omeprazole, digoxin, ranitidin, dan diazepam merupakan obat yang termasuk dalam Beers Criteria yang banyak diresepkan. Na diklofenak sebaiknya tidak diberikan pada pasien geriatri karena dapat meningkatkan risiko perdarahan gastrointestinal atau ulkus peptikum. Omeprazol pada pasien geriatri dapat meningkatkan risiko terhadap infeksi Clostridium difficile, keropos tulang dan fraktur. Digoxin dapat meningkatkan risiko toksisitas dan meningkatkan mortalitas. Ranitidin dapat menginduksi atau memperburuk delirium. Diazepam dapat meningkatkan sensitivitas terhadap benzodiazepin dan terjadi penurunan metabolisme sehingga meningkatkan risiko gangguan kognitif, delirium, jatuh, dan patah tulang (American Geriatrics Society, 2015).

\section{SIMPULAN}

Kesimpulan dari penelitian ini adalah :

1. Berdasarkan peresepan dari 300 pasien geriatri di klinik penyakit dalam RSUD K.R.M.T Wongsonegoro Semarang diketahui sebanyak 88,33\% pasien mendapatkan peresepan obat-obat yang termasuk dalam Beers Criteria tahun 2015.

2. Lima jenis obat yang termasuk dalam Beers Criteria tahun 2015 yang paling banyak diresepkan adalah na diklofenak, omeprazole, digoxin, ranitidin, dan diazepam.

3. Perlu pemberian informasi kepada dokter penulis resep tentang obat-obat yang termasuk dalam Beers Criteria karena berpotensi menimbulkan DRPs yang dapat menghambat keberhasilan terapi.

\section{UCAPAN TERIMAKASIH}

Pada kesempatan ini, peneliti ingin mengucapkan terima kasih kepada Direktur RSUD K.R.M.T Wongsonegoro Semarang yang telah mengijinkan dilakukannya penelitian ini.

\section{DAFTAR PUSTAKA}

American Geriatrics Society, 2015, American Geriatrics Society 2015 Updated Beers Criteria for Potentially Inappropriate Medication Use in Older Adults, Journal of America Geriatrics Society, 63(11):2227-46.

Anggriani, A., Lisni, I., dan Faujiah, D.R.S., 2016, Analisis Masalah Terkait Obat pada Pasien Lanjut Usia Penderita Osteoartritis di Poli Orthopedi di Salah Satu Rumah Sakit di Bandung, Kartika Jurnal Ilmiah Farmasi, 4(2):1320.

Badan Pusat Statistik, 2017, Badan Pusat Statistik Kota Semarang Tahun 2017. 
di akses 8/11/2017

https://semarangkota.bps.go.id,

Dasopang, ES., Harahap, U., dan Lindarto, D., 2015, Polifarmasi dan Interaksi Obat Pasien Usia Lanjut Rawat Jalan dengan Penyakit Metabolik, Jurnal Farmasi Klinik Indonesia, 4 (4) : 235-241.

Hanlon, JT., Schmader, KE., Koronkowski, MJ., Weinberger, M., 1997, Adverse Drug Events In High Risk Older Outpatients, Journal of American Geriatrics Society, 45(8) : 945-48.

Kemenkes RI, 2014, Penyelenggaraan Pelayanan Geriatri di Rumah Sakit Tahun 2014,

Jakarta : Kementrian Kesehatan

Republik Indonesia.

Negara, Y.R., Machlaurin, A., Rachmawati, E., 2016, Potensi Penggunaan Obat yang Tidak Tepat pada Peresepan Pasien Geriatri Rawat Jalan di RSD dr. Soebandi Jember Berdasarkan Beers Criteria, e-Jurnal Pustaka Kesehatan, 4 (1) : 14-19.

Rahmawati, Y., dan Sunarti, S. 2014. Permasalahan Pemberian Obat pada Pasien Geriatri di Ruang Perawatan RSUD Saiful Anwar Malang, Jurnal Kedokteran Brawijaya, 28 (2) : 141-145.

Rambadhe, S., Chakarborty, A., Shrivastava, A., Ptail, U.K., Rambadhe, A., 2012, A Survey on Polypharmacy and Use of Inappropriate Medications. Toxicology International, 19(1): 68-73.

Syuaib, AS. ANM., Darmawan, E., Mustofa., 2015. Penggunaan Potentially Inappropriate
Medications (PIMs) Pada Pasien Geriatri Rawat Inap Osteoarthritis Di RS PKU Muhammadiyah Yogyakarta, Pharmaciana, 5 : 7784.

Tobat, S.R., Muchtar, M.H., Martini, R.D., 2015, Identifikasi ADR (Adverse Drug Reaction) pada Pasien Geriatri di Bagian/SMF Rawat Inap Penyakit Dalam RSUP. Dr M. Djamil Padang, Scientia Jurnal Farmasi dan Kesehatan, 5 (1) :57-61.

United Nations, 2015, World Population Prospects : The 2015 revision.

http://esa.un.org/unpd/wpp/punli cation/files/key fndings_wpp_2 015.pdf, diakses tanggal $8 / 11 / 2019$. 